Portland State University

PDXScholar

$9-1-2018$

\title{
Development of a Crash Risk-Scoring Tool for Pedestrian and Bicycle Projects in Oregon
}

\author{
Yi Wang \\ Portland State University \\ Christopher M. Monsere \\ Portland State University, monsere@pdx.edu \\ Chen Chen \\ Oregon State University \\ Haizhong Wang \\ Oregon State University
}

Follow this and additional works at: https://pdxscholar.library.pdx.edu/cengin_fac

Part of the Civil and Environmental Engineering Commons

Let us know how access to this document benefits you.

\section{Citation Details}

Wang, Y., Monsere, C. M., Chen, C., \& Wang, H. (2018). Development of a Crash Risk-Scoring Tool for Pedestrian and Bicycle Projects in Oregon. Transportation Research Record, 2672(32), 30-39. https://doi.org/10.1177/0361198118794285

This Post-Print is brought to you for free and open access. It has been accepted for inclusion in Civil and Environmental Engineering Faculty Publications and Presentations by an authorized administrator of PDXScholar. Please contact us if we can make this document more accessible: pdxscholar@pdx.edu. 
Wang Monsere Chen Wang

DEVELOPMENT OF A CRASH RISK-SCORING TOOL FOR PEDESTRIAN AND BICYCLE PROJECTS IN OREGON

Yi Wang

Department of Civil and Environmental Engineering

Portland State University

P.O. Box 751

Portland, OR 97207-0751

Tel: 503-725-4208

Email: yiwang@pdx.edu

Christopher M. Monsere

Department of Civil and Environmental Engineering

Portland State University

P.O. Box 751

Portland, OR 97207-0751

Tel: 503-725-9746

Email: monsere@pdx.edu

Chen Chen

School of Civil and Construction Engineering

Oregon State University

101 Kearney Hall

Corvallis, OR 97331

Email: chenc4@oregonstate.edu

Haizhong Wang

School of Civil and Construction Engineering

Oregon State University

101 Kearney Hall

Corvallis, OR 97331

Tel: 541-737-8538

Email: Haizhong.Wang@oregonstate.edu

Word count: 4,547 words text +7 tables +2 figures x 250 words (each) $=6,797$ words

TRR Paper number: 18-00738

Submission Date: March 15, 2018 
Wang Monsere Chen Wang

\section{ABSTRACT}

Methods for identifying and prioritizing high-crash locations for safety improvements are generally crash-based. There are fewer reported crashes involving non-motorized users and, in most states, reported crashes must involve a motor vehicle. This means that minor, non-injury events are not reported and those crashes that are reported tend to be more severe. Selecting projects based only on crash performance is sometimes limiting for these crash types and predicting where these crashes will occur next is also a challenging task. An alternative to crashbased selection is to develop risk-based criteria and methods. This paper presents the results of a research effort to develop a risk-scoring method with weights derived from data for use in project screening and selection in Oregon. To develop the risk model, data were collected from 188 segments and 184 intersections randomly selected on both state and non-state roadways. Geometric, land use, volume, and crash data were collected from Google Earth, EPA's Smart Location Database and the ODOT crash database from 2009-2013. The sample included 213 bicycle and pedestrian crashes on the segments and 238 at intersections. Logistic regression models were developed and the outputs used to create pedestrian and bicycle risk-scoring tools for segments and intersections. The risk-scoring tool was applied to safety projects identified in the 2015 All Roads Transportation Safety (ARTS) project lists from Oregon. The risk scores for the case study applications aligned reasonably well with the project's benefits-costs estimates. 
Wang Monsere Chen Wang

\section{INTRODUCTION}

Methods for identifying and prioritizing high-crash locations for safety improvements are generally crash-based (1). There are fewer reported crashes involving non-motorized users and, in most states, reported crashes must involve a motor vehicle. This means that minor, non-injury events are not reported and those crashes that are reported tend to be more severe. This results in fewer crashes for network screening techniques to identify locations. Further, since there is clear evidence that the decision to make non-motorized trips by bicycling or walking are influenced by the perception of safety (2), locations that have deficient geometric or operational features may not be identified by crash-based screening methods. Exposure data for non-motorized users is also challenging to obtain at the network level (3). Selecting projects based only on crash performance is sometimes limiting for these crash types and predicting where these crashes will occur next is also a challenging task. An alternative to crash-based selection is to develop riskbased criteria and methods.

The Oregon Department of Transportation (ODOT) has identified pedestrian and bicycle crashes as a primary focus area for investing in infrastructure funding. In 2015, 17.7\% of the 445 traffic fatalities in Oregon were non-motorized (4). ODOT has appropriated approximately $\$ 4$ million annually in the All Roads Transportation Safety Program (ARTS) to address this issue. Prior to this research project, ODOT conducted a systemic safety analysis of pedestrian and bicycle safety (5). As part of the work, a crash frequency-based and risk-based prioritization methodology were developed. The quantification of risk factors and the magnitude of their influence was constrained by the additional data that the project was able to collect, and many of the risk scores were based on engineering judgment.

The objective of the research described in this paper was to develop a risk-scoring method with weights derived from data. The intent is for the risk method to be used in project screening and selection in Oregon. Following a brief background and literature summary, the data collection methodology on segments and at intersections is described. In the methodology, the logistic modeling approach and conversion of the outputs to a risk-scoring tool is described. The model results and final tool are then described. Finally, the application of the risk-scoring tool to several projects recommended for funding in the All Roads Transportation Safety (ARTS) project list is presented.

\section{BACKGROUND}

In the transportation context, risk is defined as a probability or threat of damage, injury, liability, loss, or any other negative occurrence that is caused by external or internal vulnerabilities, and that may be avoided through preemptive action. The amount of risk can be interpreted by the probability of the outcome and potential severity of the outcome if the event occurs $(6)$. For transportation and vulnerable road users, the probability is a function of exposure and consequence is a function of operating conditions (e.g., vehicle speeds and size). Risk assessment and scoring methods should include elements of exposure and expectations of the severity of the outcome.

In the general sense, the systemic safety approach has some of the elements of a risk-

based assessment. After first identifying a focus crash type, a more detailed analysis can identify, diagnose and treat locations that are at high risk for crashes on a system-wide basis (7). More directly related are the road assessment programs such as the United States Road Assessment Program (usRAP) (8). The program categorizes roadways in a number of traditional ways 
(frequency and rate of fatal crashes, the difference from average rate performance), but also includes a method to develop a road protection score. The road protection score is calculated based on the potential for severe outcomes for head-on, run-off-the-road, and intersection crashes. In this way, the assessment is not entirely crash-based and includes factors that explain the probability of a severe crash.

For non-motorized project selection and prioritization, the Pedestrian and Bicycle Safety Indices (ISI) developed for the Federal Highway Administration (FHWA) are similar in intent to a risk-scoring model. The indices allow engineers and planners to proactively identify intersection crossings and approach legs which should be the greatest priority for undergoing pedestrian and bicycle safety improvements (9). In the methodology, the ISI score is an evaluation of each approach leg of an intersection rather than evaluating the intersection as a whole. Safety ratings (opinion) from experts and bicycle/pedestrian-motorist interactions from a video analysis of each site were used to generate a multivariate linear regression model to explain the safety indices. More recently, the ActiveTrans Priority Tool (10), produced as part of National Cooperative Highway Research Program Report 803, allows users to select scoring criteria and input the weights of stakeholder input, constraints and opportunities and to prioritize the locations. While not derived from crash analysis, level of service measures such as the Highway Capacity Manual's multimodal level of service for pedestrian and bicycle facilities generally measure user comfort and convenience. These geometric and operational features have some relationship to safety as demonstrated in the literature. For bicycles, the level of traffic stress (11) is a tool only for bicycle networks. This method estimates the stress level by the criteria based on Dutch standards for bicycle facilities. Preliminary studies show that more than half of the bicycle crashes happened on streets with a higher level of stress (12).

Finally, there is a large body of literature where the severity and frequency of pedestrian and bicycle crashes have been explored. With respect to severity and crash probabilities, many studies (13-20) have used a logit model to identify the significant variables, including geometric design characteristics, driver characteristics and build environment variables, in pedestrian and bicycle crashes at both road segment and intersections.

\section{DATA}

The previous literature was used to identify key variables that should be considered in a risk model. Tables 1 and 2 summarize the list of variables that were collected and their descriptive statistics. A random sampling approach was used to select segments and intersections for data collection. Segments were selected if they were in an urban area and had arterial (minor or principal) functional classification. Both state- and non-state-owned roadways were included but ramps were excluded. A selected segment was split to be homogenous in the data elements (but only one segment was kept to minimize spatial correlations). Intersections were collected concurrently with the segment sampling process if the selected segment contained traffic control on the major road (stop or signal).

A total of 188 arterial roadway segments and 184 intersections with traffic control (traffic signal, four-way stop or roundabout) within urban areas were randomly selected. The average length of segments is roughly 706 feet. The elements of geometric design were primarily collected manually from inspection and measurement of Google Earth aerial photos, and the built environment characteristics were gathered from the U.S. Protection Agency's Smart Location Database. Traffic volume data were assembled for all segments and intersections, and all of the 
annual average daily traffic (AADT) data were calibrated to the year of 2014 using growth factors obtained from the ODOT ATR station growth factors. STRAVA Metro data was used to represent bicycle average daily traffic in this study. The dataset was purchased by ODOT for research and project purposes (OSU and PSU researchers were allowed to obtain the data under this agreement). Unpublished work by ODOT suggests that the STRAVA count can represent $1 \%$ of total bike volume without considering the difference between commuter and cyclist.

Crash data for five years, from 2009 to 2013 in Oregon, was used in this study. Crashes within a 125-foot radius buffer zone at the middle point of intersections were considered as intersection-related crashes. In total, there were 113 pedestrian crashes and 100 bicycle crashes on the segments, and 108 pedestrian crashes and 130 bicycle crashes at the intersections. As designed, the sample produced segments and intersections where there have been no crashes. As shown in Figure 1, around $20 \%$ of the segments have only one bicycle or pedestrian crash. Fewer segments, around $10 \%$, have two crashes in five years and only a few have more than two crashes. Intersections have similar patterns for pedestrian and crash frequency. Most of the intersections selected do not have crashes, and few intersections had more than two crashes from 2009 to 2013. Others have one or two pedestrian or bicycle crashes.

\section{METHODOLOGY}

Logistic regression was initially proposed by Cox in 1958 (21) to measure the categorical dependent variable (Y) and multiple independent variables $(\mathrm{X})$ by using the logistic function. It was developed based on the idea of odds which describes likelihoods of events. Specifically, the odds indicate how often something (e.g. $\mathrm{y}=1$ ) happens relative to how often it does not happen (e.g. $\mathrm{y}=0)(23)$. When developing the logistic regression equation, the $\ln$ of an odds represents a logit transformation, where the logit is a function of covariates (22):

$\operatorname{logit}\left[P_{n}\right]=\ln \left[\frac{P_{n}}{1-P_{n}}\right]=\beta_{0}+\beta_{1} x_{1, n}+\cdots+\beta_{i} x_{i, n}$

those parameters, after estimated by maximum likelihood methods, can be used to estimate the probability that the outcome takes the value one as a function of covariates using the equation below $(21,25)$ :

$P_{n}=\frac{e^{(\widehat{\beta})}}{1+e^{(\widehat{\beta})}}$ where $\hat{\beta}=\beta_{0}+\beta_{1} x_{1, n}+\cdots+\beta_{i} x_{i, n}$

where $P_{n}$ is the probability that an event (crash) happens for observation $n$ (indicates a segment or an intersection in this paper). $\beta_{0}$ is the model constant and $\beta_{1} \cdots \beta_{i}$ are the unknown parameters corresponding with the independent variables (total $i$ ). $e$ is the exponential constant approximately equal to $2.71828 ; x$ is a vector of independent variables and $\hat{\beta}$ is a vector of estimated parameters; $i$ is the total number of independent variables. This study uses the binary variable that whether bicycle crashes occurred or not on a site as the response variable and is called "crash occurrence model" thereafter. Crash frequency is transferred into crash occurrence (crash occurrence $=1$ when there was more than one crash happened; and $=0$ the otherwise) and served as a binary response variable.

However, the model coefficient cannot be used directly to interpret the slope or rate of change of the dependent variable per unit change in the independent variable in logit model due to its nonlinear feature. The logit model is developed based on odds that describe likelihoods of 
events. Odds, in equation (4), are related to probability but are conceptually and numerically different (21).

Odds $=\frac{P_{n}}{1-P_{n}}=e^{\beta_{0}+\beta_{1} x_{1, n}+\cdots+\beta_{i} x_{i, n}}$

Meaningful interpretation of coefficients in logistic models relies on how to interpret the difference between two odds (25). Equation (2) shows that the logit model is linear in the logit. Especially for a unit change in $x_{i}$, we expect the logit change by $\beta_{i}$, holding all other variables constant. The odds ratio, which is shown in Equation (5), compares the likelihood of two odds and provides a meaningful interpretation of coefficients. If the odds ratio is greater than 1 , it represents the likelihood of an event with changing one unit in one variable (indicated in the numerator) is greater than the likelihood of the event with original value in variables (indicated in the denominator).

Odds Ratio $=\psi=\frac{\text { odds of an event with increase one unit in one variable }}{\text { odds of an event }}=\frac{\left(\frac{P_{n}(i)}{1-P_{n}(i)}\right)^{*}}{\left(\frac{P_{n}(i)}{1-P_{n}(i)}\right)}=$

$\frac{e^{\beta_{0}+\beta_{1} x_{1, n}+\cdots+\beta_{i}\left(x_{i, n}+1\right)}}{e^{\beta_{0}+\beta_{1} x_{1, n}+\cdots+\beta_{i} x_{i, n}}}=e^{\beta_{i}}$

where $\left(\frac{P_{n}(i)}{1-P_{n}(i)}\right)^{*}$ is the odds that an event with changing one unit in one variable (i.e. $x_{i, n}+1$ ) happens whereas $\left(\frac{P_{n}(i)}{1-P_{n}(i)}\right)$ is the odds that the event with original value in variables happens. $e^{\beta_{i}}$ is the odds ratio that indicates the relative amount by which the odds of an outcome change when the value of a corresponding independent variable increases by one unit (23).

The model results were then converted to a risk score based on the odds ratio. Conversion to a risk score creates an easy method for interpreting and applying the modeling results. For each type of facility and user, the maximum risk score is set to 100 . The distribution of 100 points to each of the variables was weighted. Additional details on this process can be found in the project's final report (26). The risk scores are comparable for a facility and user type but not across the categories (i.e., the scores from the pedestrian segments are not comparable to the bicycle intersections). Comparison across the categories can be done by estimating the risk score percentile (discussed in the application section).

\section{RESULTS}

To develop the logit models, a combined backward and forward stepwise method (27) was initially used to determine the significant variables to be included in the model, then other possible variables (based on engineering judgment and literature) were also explored. The dependent variable was the presence of a crash or not ( 0 or 1$)$. Table 3 summarizes the final selected model for pedestrian segments and intersections. Table 5 translates the model parameters into the risk score. In this modeling effort, the significant variables should not be interpreted as recommendations for engineering-level improvements. The variables are, in many cases, explaining more about the safety of the location than the individual variable. Design-level safety decisions should use more robust tools such as the Highway Safety Manual (1).

For pedestrian segments, the significant variables are reasonable and the direction of effect is as expected. The model includes variables of exposure and risk. The odds ratio for the travel direction (one-way to two-way) indicates that the odds of a pedestrian crash happening on a segment are 0.276 times smaller, holding all other variables constant. These results likely 
reflect some association with more traffic and lanes on one-way streets. The presence of parking increases the odds of pedestrian crashes (more pedestrian activity). The effect of increased posted speeds on the probability of crashes is in the expected direction (an increase in speed increases the probability of a crash outcome). The continuous nature of how the speed was modeled also means that the effect is not linear, and that larger speeds have a very significant effect on the overall probability prediction. The presence of a two-way left-turn lane (TWLTL) would also increase crash potential. The hypothesis is that the additional width and turning conflicts add additional risk for pedestrians or higher volumes associated with TWLTL roads. As a measure of pedestrian activity, the total population density coefficients indicate that crash probability increases with population density.

For pedestrians at intersections, the final model includes total population density; the number of transit lines through the intersection; the number of major-road right-turn lanes; the major-road AADT in 2014; the presence of a median on the minor road; and the number of rightturn lanes the minor road. The density and transit variables reflect pedestrian activity levels and the direction is as expected (increased probability with increases in these measures). Similarly, the coefficient of major-road AADT was significant and positive. The presence of right-turn lanes on the major road is associated with an increased probability. The lack of a median on the major road also increases the crash probability. However, on the minor roadway, the coefficient for the presence of a right-turn lane on the minor road is not as expected.

Table 4 summarizes the final selected model for bicycle segments and intersections, including model coefficients, standard error, p-value, significance and odds ratios. Table 6 translates the model parameters into the risk score. Unlike the pedestrian models, few variables were found to be significant in the bicycle models, especially for the segment model. For the bicycle intersection models, the significant variables include bicycles per day, the number of transit stops, the minor-road functional class, minor-road total traffic lanes, and minor-road rightturn lanes. Clearly, the number of bicycles per day captures the increased exposure as volumes increase. The number of transit stops indicates a presence of other road users and possibly additional interactions with bus traffic. The number of lanes on the minor road can be interpreted as increasing the total intersection size.

For the bicycle segment model, the significant variables include the presence of crossing (no crossing is the base condition); AADT (factored to 2014); three-leg intersection density; and bike volume (per day). Unlike all the other crash occurrence models, very few variables were found to be significant in the model. The final selected model includes variables at a lower confidence level for significance than the other models. The final model does include an exposure metric for bicycles per day and the sign is expected (as bicycles per day increase then probability also increases). Three-leg intersection density (hypothesized to be associated with less connectivity) is associated with a positive increase in crash probability. Vehicle volume, represented by AADT in the model, has the positive coefficients as expected, indicating that high vehicle volume could lead to high risk for bicyclists on this segment. The presence of crossings decreases the probability of bicycle crashes on the segments. It is hypothesized that the presence of pedestrian crossings is related to the overall design of the roadway (i.e., a more nonmotorized, user-friendly character). 
Wang Monsere Chen Wang

\section{APPLICATION}

The risk-scoring tables were applied to all segment and intersection samples in the modeling dataset. Figure 2 shows the distribution of scores for each of the risk tools as applied to these locations, and the percentile and mean values of these distributions. With the exception of the intersection tool for pedestrians, the distributions are skewed. The bicycle segment model is less distributed, reflecting the limited number of significant variables that were in the model. The risk scores are only intended to be evaluated within each context (i.e., the risk score for bicycles at intersections is not comparable to the score for pedestrians on segments). The distributions of the risk scores could be used when making comparisons across the tools by estimating the percentile of the score. The values for the $25^{\text {th }}, 50^{\text {th }}$ and $75^{\text {th }}$ percentile are shown in Figure 2 . For example, a risk score of 46 would be above the 75th percentile of the calculated scores for the pedestrian segment and bicycle intersection risk scores, but only average for the other two tools.

To further demonstrate the application of the tool, a total of 10 intersection projects was selected from the ARTS final project list in the more urban ODOT regions. The projects are listed in Table 7, including brief descriptions of the proposed project elements. Table 7 also includes the projects' benefit-to-cost ratio $(\mathrm{B} / \mathrm{C})$ as reported by ODOT. To calculate the risk score, the values for each of the variables at the project location were collected, then the risk scores for each variable (shown in Table 3 (for pedestrians) and Table 5 (for bicycle)) were summed to compute a project risk score. As a reminder, the risk scores between the two types are not comparable. Therefore, the risk score percentile is also shown in Table 7.

As the projects listed in Table 7 were the final projects selected through the ARTS process, it is expected that the projects with higher $\mathrm{B} / \mathrm{C}$ value also have higher risk scores. The application of the risk scores corresponds well to the project's final $\mathrm{B} / \mathrm{C}$ value. Referring to Table 7, the risk scores for the projects with the two highest $\mathrm{B} / \mathrm{C}$ ratios are above the 75 th percentile score (55) of pedestrian intersection models. The lower-ranked B/C projects correspond to lower percentiles of the risk score. A similar exercise was conducted for another five intersection projects that relate to bicycles. As shown, the higher risk scores align with the higher $\mathrm{B} / \mathrm{C}$ ratios with the exception of the Albany project. The 75 th percentile risk score is 42.75; all of the projects are below this value.

\section{CONCLUSION}

In this study, the research team developed a method to identify and prioritize locations with quantitative risk factors of pedestrian and bicycle crashes, not merely based on crash histories. A database of 188 segments and 184 intersections, including detailed geometric and operational elements as well as broad descriptors of the built environment, is assembled for analysis. Logistic regression models for the crash occurrence (crash or not) were developed and a method was developed to create a risk-scoring tool for pedestrians and bicycles at intersections and segments (a total of four scoring tools) using the model results. To demonstrate the application of the risk-scoring tool, the tool was applied to safety projects that were recommended in 2015 All Roads Transportation Safety (ARTS) project lists.

The primary challenge to quantifying the risk for pedestrian and bicycles is the missing measures of exposure and the relatively few pedestrian and bicycle crashes observed on most segments and intersections. The inclusion of the bicycle STRAVA data significantly improved the bicycle models, though the data's ability to accurately represent all bicycle travel is still somewhat uncertain. 
In this research, the value of each risk score was derived from the modeling output. All models suffer from the limitations of the input data set. With a larger or different sample for modeling, there is a possibility that the risk scores would be different. The inclusion of exposure measures would likely improve the modeling results. Finally, it is clear that a larger dataset, perhaps derived from GIS or automated data mining tools, would produce a very robust database for a similar modeling effort. Rather than a statewide focus, a regional or MPO-level analysis would likely yield good results leveraging the more detailed spatial data available.

\section{ACKNOWLEDGEMENTS}

This work was funded by SPR research program of the Oregon Department of Transportation, project SPR 779.

\section{AUTHOR CONTRIBUTION STATEMENT}

The authors confirm contribution to the paper as follows: study conception and design: C. Monsere and H. Wang; data collection: C. Chen and Y. Wang; analysis and interpretation of results: Y. Wang, C. Chen, C. Monsere and H. Wang; draft manuscript preparation: all authors. All authors reviewed the results and approved the final version of the manuscript. 
Wang Monsere Chen Wang

\section{REFERENCES}

1. AASHTO, Highway Safety Manual. American Association of State Highway and Transportation Officials (AASHTO). Washington, DC, 2010.

2. Dill, J. Bicycling for Transportation and Health: The Role of Infrastructure, Journal of Public Health Policy, 30, 2009, pp 95-110. http:/dx.doi.org/10.1057/jphp.2008.56

3. Figliozzi, M., P. Johnson, C. Monsere, K. Nordback. Methodology to Characterize Ideal Short-Term Counting Conditions and Improve AADT Estimation Accuracy Using a Regression-Based Correcting Function. Journal of Transportation Engineering, 140(5), 2014, pp. 1-16. http://dx.doi.org/10.1061/(ASCE)TE.1943-5436.0000663.

4. Oregon Traffic Crash Summary (2015). Transportation Data Section, Crash Analys is and Reporting Unit, Oregon Department of Transportation, Salem, OR, 2017

5. Oregon DOT Pedestrian and Bicycle Safety Implementation Plan. Kittelson \& Associates, Inc. 2014.

6. Berdica, K. An Introduction to Road Vulnerability: What Has Been Done, Is Done and Should Be Done. Transport policy, 9(2), 2002. pp. 117-127. https://doi.org/10.1016/S0967070X(02)00011-2

7. Preston, H., R. Storm, J.D. Bennett, and B. Wemple. Systemic Safety Project Selection Tool. (No. Publication FHWA-SA-13-019. FHWA, U.S. Department of Transportation, 2013.

8. Harwood, D. W., D. K. Gilmore, D. J. Torbic, R. Souleyrette, and Z.N. Hans. United States Road Assessment Program: Pilot Program: Phase II. Final Report. AAA Foundation for Traffic Safety, Washington D.C. 2008.

9. Carter, D. L., W. W.Hunter, C.V. Zegeer, J.R. Stewart, H. Huang, Pedestrian and bicyclist intersection safety indices. Publication FHWA-HRT-06-125, FHWA, U.S. Department of Transportation, 2006

10. Lagerwey, P. A., Hintze, M. J., Elliott, J. B., Toole, J. L., \& Schneider, R. J. NCHRP Report 803: Pedestrian and Bicycle Transportation Along Existing Roads-ActiveTrans Priority Tool Guidebook. Transportation Research Board, Washington D.C., 2015. https:/dx.doi.org/10.17226/22163

11. Furth, P. G., Mekuria, M. C., \& Nixon, H. (2016). Network Connectivity for Low-Stress Bicycling. Transportation Research Record: Journal of the Transportation Research Board, No. 2587, 2016, pp. 41-49 https://doi.org/10.3141/2587-06.

12. Wang H, M. Palm, C. Chen, R. Vogt, and Y. Wang. Does Bicycle Network Level of Traffic Stress (LTS) Explain Bicycle Travel Behavior? Mixed Results from an Oregon Case Study. Journal of Transportation Geography. 2016;57. 2016. pp. 8-18. http://dx.doi.org/10.1016/j.jtrangeo.2016.08.016.

13. Eluru, N., C.R. Bhat, D. Hensher, D. A Mixed Generalized Ordered Response Model for Examining Pedestrian and Bicyclist Injury Severity Level in Traffic Crashes. Accident Analysis \& Prevention, 40(3), 2008. pp. 1033-1054. https://doi.org/10.1016/j.aap.2007.11.010 
Wang Monsere Chen Wang

14. Kim, J. K., S. Kim, G.F. Ulfarsson, and L.A. Porrello, Bicyclist Injury Severities in BicycleMotor Vehicle Accidents. Accident Analysis \& Prevention, 39(2), 2007. pp. 238-251. https://doi.org/10.1016/j.aap.2006.07.002

15. Pai, C. W. Overtaking, Rear-end, and Door Crashes Involving Bicycles: An Empirical Investigation. Accident Analysis \& Prevention, 43(3), 2011. pp. 1228-1235. https://doi.org/10.1016/j.aap.2011.01.004

16. Boufous, S., L. de Rome, T. Senserrick, and R. Ivers. Risk Factors for Severe Injury in Cyclists Involved in Traffic Crashes in Victoria, Australia. Accident Analysis \& Prevention, 49, 2012. pp. 404-409. https://doi.org/10.1016/j.aap.2012.03.011

17. Schepers, P., and B. den Brinker. What Do Cyclists Need to See to Avoid Single-Bicycle Crashes? Ergonomics, 54(4), 2011. pp. 315-327. https://doi.org/10.1080/00140139.2011.558633

18. Parkin, J., M. Wardman, and M. Page. Models of Perceived Cycling Risk and Route Acceptability. Accident Analysis \& Prevention, 39(2), 2007. pp. 364-371. https://doi.org/10.1016/j.aap.2006.08.007

19. Lenguerrand, E., J. L. Martin and B. Laumon, Modelling the Hierarchical Structure of Road Crash Data-Application to Severity Analysis. Accident Analysis \& Prevention, 38(1), 2006. pp. 43-53. https://doi.org/10.1016/j.aap.2005.06.021

20. Jang, K., Park, S., Kang, S., Song, K., Kang, S., and Chung, S. Evaluation of Pedestrian Safety: Pedestrian Crash Hot Spots and Risk Factors for Injury Severity. Transportation Research Record: Journal of the Transportation Research Board, No. 2393, 2013, pp. 104-116 https://doi.org/10.3141/2393-12.

21. Walker, S. H. and D.B. Duncan, Estimation of the Probability of an Event as a Function of Several Independent Variables. Biometrika, 54(1-2), 1967. pp. 167-179.

22. Long, S. J. Regression Models for Categorical and Limited Dependent Variables. Advanced Quantitative Techniques in the Social Sciences, 7. 1997.

23. Washington, S., M.G. Karlaftis, and F.L. Mannering, Statistical and Econometric Methods for Transportation Data Analysis. 2nd Edition. 2011.

24. Hernandez, S., E. L. Jessup, J. Anderson, E. North. Uncovering Confounding Factors of Large-Truck Crashes and Safety Critical Events: An Exploratory Analys is of a Northwest Truck Driver Survey. Presented at the 58th Transportation Research Forum Annual Conference. Chicago, Il. 2017.

25. Al-Ghamdi, A. S. Using Logistic Regression to Estimate the Influence of Accident Factors On Accident Severity. Accident Analysis \& Prevention, 34(6), 2002. pp. 729-741. https://doi.org/10.1016/S0001-4575(01)00073-2

26. Monsere, C. H. Wang, Y. Wang and C. Chen. Risk Factors for Pedestrian and Bicycle Crashes. Publication FHWA-OR-RD-17-13. Oregon DOT. Salem, OR. 2017

27. Montgomery, D. C., E. A. Peck, C.G. Vining, Introduction to Linear Regression Analysis. John Wiley \& Sons. 2015. 
Wang Monsere Chen Wang

\section{LIST OF TABLES}

TABLE 1 Summary of Categorical Variables

TABLE 2 Summary of Continuous Variables

TABLE 3 Pedestrian Modeling Results

TABLE 4 Bicycle Modeling Results

TABLE 5 Summary of Risk Scores for Pedestrians

TABLE 6 Summary of Risk Scores for Bicycles

TABLE 7 Application of Risk Scores to Selected Intersection Projects 
Wang Monsere Chen Wang

\section{LIST OF FIGURES}

FIGURE 1: Number of Segments and Intersections by Crash Frequency.

FIGURE 2 Risk-Score Distribution for Each Type and User. 
Wang Monsere Chen Wang

TABLE 7 Summary of Categorical Variables

\begin{tabular}{|c|c|c|c|c|}
\hline & \multicolumn{2}{|l|}{ Variable } & Frequency & Percentage \\
\hline \multirow[t]{17}{*}{ Segments } & \multirow{4}{*}{$\begin{array}{l}\text { Number of traffic lanes } \\
\text { (excluding two-way left-turn } \\
\text { lane) }\end{array}$} & 1 Lane & 2 & $1.06 \%$ \\
\hline & & 2 Lane & 112 & $59.57 \%$ \\
\hline & & 3 Lane & 16 & $8.51 \%$ \\
\hline & & $\begin{array}{l}4 \text { Lanes or } \\
\text { more }\end{array}$ & 58 & $30.85 \%$ \\
\hline & \multirow{2}{*}{$\begin{array}{l}\text { Presence of two-way left-turn } \\
\text { lane (TWLTL) }\end{array}$} & No & 130 & $69.15 \%$ \\
\hline & & Yes & 58 & $30.85 \%$ \\
\hline & \multirow{2}{*}{$\begin{array}{l}\text { Presence of marked midblock } \\
\text { crosswalks within segment }\end{array}$} & No & 181 & $96.28 \%$ \\
\hline & & Yes & 7 & $3.72 \%$ \\
\hline & \multirow{2}{*}{ Presence of on-street parking } & No & 143 & $76.06 \%$ \\
\hline & & Yes & 45 & $23.94 \%$ \\
\hline & \multirow[t]{2}{*}{ Traffic direction } & One-way & 24 & $12.77 \%$ \\
\hline & & Two-way & 164 & $87.23 \%$ \\
\hline & \multirow[t]{5}{*}{ Posted speed limit (mph) } & 20 & 12 & $6.38 \%$ \\
\hline & & 25 & 40 & $21.28 \%$ \\
\hline & & 30 & 27 & $14.36 \%$ \\
\hline & & 35 & 79 & $42.02 \%$ \\
\hline & & $>35$ & 30 & $15.96 \%$ \\
\hline \multirow[t]{19}{*}{ Intersections } & \multirow[t]{2}{*}{ Intersection legs } & 4-Leg & 157 & $85.33 \%$ \\
\hline & & 3-Leg & 27 & $14.67 \%$ \\
\hline & \multirow{2}{*}{$\begin{array}{l}\text { Major road. Presence of right-turn } \\
\text { lane }\end{array}$} & No & 133 & $72.28 \%$ \\
\hline & & Yes & 51 & $27.72 \%$ \\
\hline & \multirow[t]{2}{*}{ Major road. Presence of median } & No & 165 & $89.67 \%$ \\
\hline & & Yes & 19 & $10.33 \%$ \\
\hline & \multirow[t]{2}{*}{ Minor road. Functional class } & Arterial & 92 & $50.00 \%$ \\
\hline & & Collector & 92 & $50.00 \%$ \\
\hline & \multirow{2}{*}{$\begin{array}{l}\text { Minor road. Presence of right- } \\
\text { turn lane }\end{array}$} & No & 120 & $65.22 \%$ \\
\hline & & Yes & 64 & $34.78 \%$ \\
\hline & \multirow{4}{*}{$\begin{array}{l}\text { Minor road. Total number of } \\
\text { traffic lanes }\end{array}$} & 2 & 43 & $23.37 \%$ \\
\hline & & 3 & 90 & $48.91 \%$ \\
\hline & & 4 & 26 & $14.13 \%$ \\
\hline & & $>4$ & 25 & $13.59 \%$ \\
\hline & \multirow{5}{*}{$\begin{array}{l}\text { Number of transit lines that go } \\
\text { through the intersection }\end{array}$} & 0 & 34 & $18.48 \%$ \\
\hline & & 1 & 90 & $48.91 \%$ \\
\hline & & 2 & 49 & $26.63 \%$ \\
\hline & & 3 & 9 & $4.89 \%$ \\
\hline & & $>3$ & 2 & $1.09 \%$ \\
\hline
\end{tabular}


Wang Monsere Chen Wang

TABLE 8 Summary of Continuous Variables

\begin{tabular}{l|l|l}
\hline Variable & Mean & $\begin{array}{l}\text { Standard } \\
\text { Deviation }\end{array}$ \\
\hline Total population density (people per square mile) & 4086.92 & 5333.08 \\
\hline Three-leg intersection density (per square mile) & 162.66 & 110.12 \\
\hline Number of transit lines through intersection & 1.36 & 1.18 \\
\hline Major road AADT & $14,080.34$ & $8,143.53$ \\
\hline Minor road AADT & $7,648.98$ & $5,480.24$ \\
\hline Segment AADT & $10,806.27$ & $7,607.40$ \\
\hline Bicycle volume, Intersection & 261.26 & 641.24 \\
\hline Bicycle volume, Segment & 94.32 & 165.37 \\
\hline
\end{tabular}


Wang Monsere Chen Wang

TABLE 9 Pedestrian Modeling Results

\begin{tabular}{|c|c|c|c|c|c|}
\hline Variable & Coefficients & $\begin{array}{l}\text { Standard } \\
\text { Error }\end{array}$ & $\mathrm{P}$-value & $\begin{array}{l}\text { Significanc } \\
\mathrm{e}\end{array}$ & $\begin{array}{l}\text { Odds } \\
\text { Ratio }\end{array}$ \\
\hline \multicolumn{6}{|c|}{ Segments } \\
\hline Travel direction (one-way or two-way) & -1.289 & 1.018 & 0.001 & $* * *$ & 0.276 \\
\hline Presence of on-street parking & 1.337 & 0.514 & 0.012 & $*$ & 3.808 \\
\hline Presence of two-way left-turn lane & 1.071 & 0.384 & 0.005 & ** & 2.918 \\
\hline Posted speed limit (mph) & 0.047 & 0.027 & 0.082 & . & 1.048 \\
\hline $\begin{array}{l}\text { Total population density (people per square } \\
\text { mile) }\end{array}$ & 0.0017 & 0.00006 & 0.006 & $* *$ & 1.002 \\
\hline $\begin{array}{l}\text { Number of traffic lanes (excluding two-way } \\
\text { left-turn lane) }\end{array}$ & 0.370 & 0.016 & 0.023 & $*$ & 1.447 \\
\hline \multicolumn{6}{|c|}{$\begin{array}{l}\text { Null deviance: } 249.16 \text { on } 188 \text { degrees of freedom Residual deviance: } 204.62 \text { on } 182 \text { degrees of freedom AIC } \\
218.62\end{array}$} \\
\hline \multicolumn{6}{|c|}{$\begin{array}{ll} & \text { Inters ections } \\
\end{array}$} \\
\hline $\begin{array}{l}\text { Total population density (people per square } \\
\text { mile) }\end{array}$ & 0.00024 & 0.000072 & 0.000 & *** & 1.000 \\
\hline Number of transit lines through intersection & 0.383 & 0.208 & 0.065 & . & 1.467 \\
\hline Major road, number of right-turn lanes & 0.784 & 0.432 & 0.070 & . & 2.190 \\
\hline Major road, AADT 2014 & 0.000063 & 0.000023 & 0.005 & $* *$ & 1.000 \\
\hline Major road, presence of median & -1.260 & 0.664 & 0.058 & . & 0.284 \\
\hline Minor road, number of right-turn lanes & -1.312 & 0.440 & 0.003 & $* *$ & 0.269 \\
\hline \multicolumn{6}{|c|}{$\begin{array}{l}\text { Null deviance: } 238.99 \text { on } 183 \text { degrees of freedom Residual deviance: } 195.40 \text { on } 177 \text { degrees of freedom } \\
\text { AIC: } 209.4\end{array}$} \\
\hline
\end{tabular}


Wang Monsere Chen Wang

TABLE 10 Bicycle Modeling Results

\begin{tabular}{|c|c|c|c|c|c|}
\hline Variable & Coefficients & $\begin{array}{l}\text { Standard } \\
\text { Error }\end{array}$ & $\mathrm{P}$-value & Significance & Odds Ratio \\
\hline \multicolumn{6}{|c|}{ Segments } \\
\hline $\begin{array}{lcc}\text { Presence of marked } & \text { midblock } \\
\text { crosswalks within segment } & \\
\end{array}$ & -1.207 & -3.662 & 0.000976 & $* * *$ & 0.2991 \\
\hline AADT 2014 & 0.00003187 & 0.00002124 & 0.1336 & & 1.00003187 \\
\hline $\begin{array}{l}\text { Three-leg intersection density (per } \\
\text { square mile) }\end{array}$ & 0.002087 & 0.001486 & 0.1602 & & 1.002089 \\
\hline Bicycles per day (STRAVA) & 0.001007 & 0.000994 & 0.3110 & & 1.0010012 \\
\hline \multicolumn{6}{|c|}{$\begin{array}{l}\text { Null deviance: } 240.60 \text { on } 188 \text { degrees of freedom Residual deviance: } 220.35 \text { on } 183 \text { degrees of freedom AIC: } \\
230.35\end{array}$} \\
\hline \multicolumn{6}{|c|}{ Intersections } \\
\hline Bicycles per day (STRAVA) & 0.00146 & 0.00024 & 0.0368 & * & 1.001 \\
\hline Number of transit stops & 0.3507 & 0.1924 & 0.0683 & . & 1.420 \\
\hline Minor functional class (arterialas base) & -0.9096 & 0.3585 & 0.0112 & * & 0.4027 \\
\hline $\begin{array}{l}\text { Minor road, total number of traffic } \\
\text { lanes }\end{array}$ & 0.49698 & 0.2067 & 0.0231 & $*$ & 1.644 \\
\hline Minor road, presence of right-turn lane & -0.7056 & 0.3581 & 0.0488 & $*$ & 0.4938 \\
\hline
\end{tabular}

Null deviance : 232.04 on 167 degrees of freedom Residual deviance : 200.04 on 161 degrees of freedom AIC: 214.04

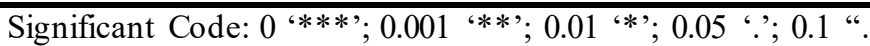


TABLE 11 Summary of Risk Scores for Pedestrians

\begin{tabular}{|c|c|c|}
\hline \multicolumn{3}{|c|}{ Segments } \\
\hline Variables & Levels & Risk Score \\
\hline \multirow{5}{*}{$\begin{array}{l}\text { Total population density (per square } \\
\text { mile) }\end{array}$} & $<=1000$ & 0 \\
\hline & $1001-3000$ & 6 \\
\hline & $3001-5000$ & 8 \\
\hline & $5001-7000$ & 11 \\
\hline & $>7000$ & 20 \\
\hline \multirow{2}{*}{ Traffic direction } & One-way & 17 \\
\hline & Two-way & 0 \\
\hline \multirow{2}{*}{ On-s treet parking } & Yes & 17 \\
\hline & No & 0 \\
\hline \multirow{4}{*}{ Posted speed limit (mph) } & $<=25$ & 0 \\
\hline & 30 & 6 \\
\hline & 35 & 8 \\
\hline & $>35$ & 12 \\
\hline \multirow{2}{*}{ Presence of TWLTL } & Yes & 14 \\
\hline & No & 0 \\
\hline \multirow{3}{*}{ Total traffic lanes } & 2 & 0 \\
\hline & 3 or 4 & 10 \\
\hline & $>4$ & 20 \\
\hline
\end{tabular}

\begin{tabular}{|c|c|c|}
\hline \multicolumn{3}{|c|}{ Intersection } \\
\hline Variables & Levels & Risk Score \\
\hline \multirow{5}{*}{$\begin{array}{l}\text { Total population density (per square } \\
\text { mile) }\end{array}$} & $<=1000$ & 0 \\
\hline & $1001-3000$ & 5 \\
\hline & $3001-5000$ & 8 \\
\hline & $5001-7000$ & 13 \\
\hline & $>7000$ & 21 \\
\hline \multirow{5}{*}{$\begin{array}{l}\text { Number of transit lines with routes } \\
\text { through intersection }\end{array}$} & 0 (base) & 0 \\
\hline & 1 & 6 \\
\hline & 2 & 8 \\
\hline & 3 & 12 \\
\hline & $>3$ & 25 \\
\hline \multirow{6}{*}{ Major AADT (2014) } & $<=5000$ & 0 \\
\hline & $5001-10000$ & 5 \\
\hline & $10001-15000$ & 7 \\
\hline & $15001-20000$ & 10 \\
\hline & $20001-25000$ & 13 \\
\hline & $>25000$ & 18 \\
\hline \multirow{2}{*}{ Presence of median on major road } & Yes & 0 \\
\hline & No & 13 \\
\hline \multirow{2}{*}{ Minor road, presence of right-turn lanes } & Yes & 0 \\
\hline & No & 15 \\
\hline \multirow{2}{*}{ Major road, presence of right-turn lanes } & No & 0 \\
\hline & Yes & 8 \\
\hline
\end{tabular}


Wang Monsere Chen Wang

\section{TABLE 12 Summary of Risk Scores for Bicycles}

\begin{tabular}{l|c|c}
\hline \multicolumn{2}{|c}{ Segments } \\
\hline Variables & Levels & Risk Score \\
\hline \multirow{4}{*}{ Bikes per day (STRAVA) } & $<=200$ & 0 \\
\cline { 2 - 3 } & $201-800$ & 15 \\
\cline { 2 - 3 } & $>800$ & 25 \\
\hline \multirow{4}{*}{ AADT } & $<=5000$ & 0 \\
\cline { 2 - 3 } & $5001-10000$ & 12 \\
\cline { 2 - 3 } & $10001-15000$ & 14 \\
\cline { 2 - 3 } & $15001-20000$ & 16 \\
\cline { 2 - 3 } & $20001-25000$ & 19 \\
\cline { 2 - 3 } square mile (EPA Smart Location) & $>25000$ & 25 \\
\cline { 2 - 3 } & $1-150$ & 0 \\
\hline \multirow{2}{*}{ Presence of marked crosswalk } & $>200$ & 13 \\
\cline { 2 - 3 } & Yes & 0 \\
\hline
\end{tabular}

\begin{tabular}{l|c|c}
\hline \multicolumn{3}{|c}{ Intersections } \\
\hline Variables & Levels & Risk Score \\
\hline \multirow{2}{*}{ Bikes per day (STRAVA) } & $<=200$ (base) & 0 \\
\cline { 2 - 3 } & $<=800$ & 11 \\
\cline { 2 - 3 } & $>800$ & 20 \\
\hline \multirow{4}{*}{ Number of transit stops } & 0 (base) & 0 \\
\cline { 2 - 3 } & 1 & 7 \\
\cline { 2 - 3 } & 2 & 10 \\
\cline { 2 - 3 } & 3 & 14 \\
\cline { 2 - 3 } & $>3$ & 27 \\
\hline \multirow{2}{*}{ Minor functional class } & Collector & 0 \\
\cline { 2 - 3 } & Arterial & 12 \\
\hline \multirow{2}{*}{ Minor road total number of traffic lanes } & 2 (base) & 0 \\
\cline { 2 - 3 } & 3 & 8 \\
\cline { 2 - 3 } & 4 & 12 \\
\cline { 2 - 3 } & $>4$ & 31 \\
\hline \multirow{2}{*}{ Minor road presence of right-turn lane } & Yes (base) & 0 \\
\cline { 2 - 3 } & No & 10 \\
\hline
\end{tabular}


Wang Monsere Chen Wang

TABLE 7 Application of Risk Scores to Selected Intersection Projects

\begin{tabular}{|c|c|c|c|c|c|c|}
\hline \multirow[t]{5}{*}{ Pedestrian } & Keizer & $\begin{array}{l}\text { Project Name } \\
\text { RIVER RD NE@ } \\
\text { SAM ORCUTT } \\
\text { WAYNE }\end{array}$ & $\begin{array}{l}\text { Proposed Project } \\
\text { Elements } \\
\text { Install No Pedestrian } \\
\text { Phase Feature with } \\
\text { Flashing Yellow Arrow }\end{array}$ & $\begin{array}{l}\mathrm{B} / \mathrm{C} \\
17.16\end{array}$ & $\begin{array}{l}\text { Risk } \\
\text { Score } \\
67\end{array}$ & $\begin{array}{l}\text { Risk } \\
\text { Percentile } \\
\quad>75^{\text {th }}\end{array}$ \\
\hline & Beaverton & $\begin{array}{l}\text { SW HALL BLVD } \\
@ \text { SW NIMBUS } \\
\text { AVE }\end{array}$ & $\begin{array}{l}\text { Install Pedestrian } \\
\text { Countdown Timer(s) }\end{array}$ & 17 & 63 & $>75^{\text {th }}$ \\
\hline & Eugene & $\begin{array}{l}\text { I 105@ MP 1.8: } \\
\text { COBURG RD @ } \\
\text { MLK JR BLVD }\end{array}$ & $\begin{array}{l}\text { Install No Pedestrian } \\
\text { Phase Feature with } \\
\text { Flashing Yellow Arrow; } \\
\text { Install Urban Green Bike } \\
\text { Lanes at Conflict Points }\end{array}$ & 9.87 & 58 & $>75^{\text {th }}$ \\
\hline & Albany & $\begin{array}{lrl}\text { GEARY ST } & \text { @ } \\
\text { QUEEN AVE }\end{array}$ & $\begin{array}{l}\text { Install Pedestrian } \\
\text { Countdown Timer(s) }\end{array}$ & 7.13 & 46 & $=50^{\text {th }}$ \\
\hline & Salem & $\begin{array}{l}\text { BROADWAY ST } \\
\text { NE@PINE ST NE }\end{array}$ & $\begin{array}{l}\text { Install No Pedestrian } \\
\text { Phase Feature with } \\
\text { Flashing Yellow Arrow }\end{array}$ & 2.45 & 53 & $=75^{\text {th }}$ \\
\hline \multirow[t]{5}{*}{ Bicycles } & Salem & $\begin{array}{lrrr}\mathrm{D} & \mathrm{ST} & \mathrm{NE} & @ \\
\text { LANCASTER } & \text { DR } \\
\mathrm{NE} & & \end{array}$ & $\begin{array}{l}\text { Install Urban Green Bike } \\
\text { Lanes at Conflict Points; } \\
\text { Add No Pedestrian Phase } \\
\text { Feature with Flashing } \\
\text { Yellow Arrow }\end{array}$ & 20.66 & 40 & $<50^{\text {th }}$ \\
\hline & Salem & $\begin{array}{l}\text { FAIRVIEW AVE } \\
\text { SE @ 12TH ST SE }\end{array}$ & $\begin{array}{l}\text { Install Urban Green Bike } \\
\text { Lanes at Conflict Points }\end{array}$ & 20.06 & 18 & $<25^{\text {th }}$ \\
\hline & Portland & $\begin{array}{l}\text { LOMBARD ST @ } \\
\mathrm{N} \text { INTERSTATE } \\
\text { AVE(US 30B) }\end{array}$ & $\begin{array}{l}\text { Install Pedestrian } \\
\text { Countdown Timer(s) }\end{array}$ & 16.80 & 28 & $<50^{\text {th }}$ \\
\hline & Albany & $\begin{array}{lrl}\text { GEARY ST } & @ \\
\text { QUEEN AVE } & \end{array}$ & $\begin{array}{l}\text { Install No Pedestrian } \\
\text { Phase Feature with } \\
\text { Flashing Yellow Arrow; } \\
\text { Install Urban Green Bike } \\
\text { Lanes at Conflict Points }\end{array}$ & 7.13 & 34 & $>50^{\text {th }}$ \\
\hline & Eugene & $\begin{array}{l}\text { RIVER RD } \\
\text { IRVING RD }\end{array}$ & $\begin{array}{l}\text { Install Urban Green Bike } \\
\text { Lanes at Conflict Points }\end{array}$ & 2.45 & 18 & $<25^{\text {th }}$ \\
\hline
\end{tabular}




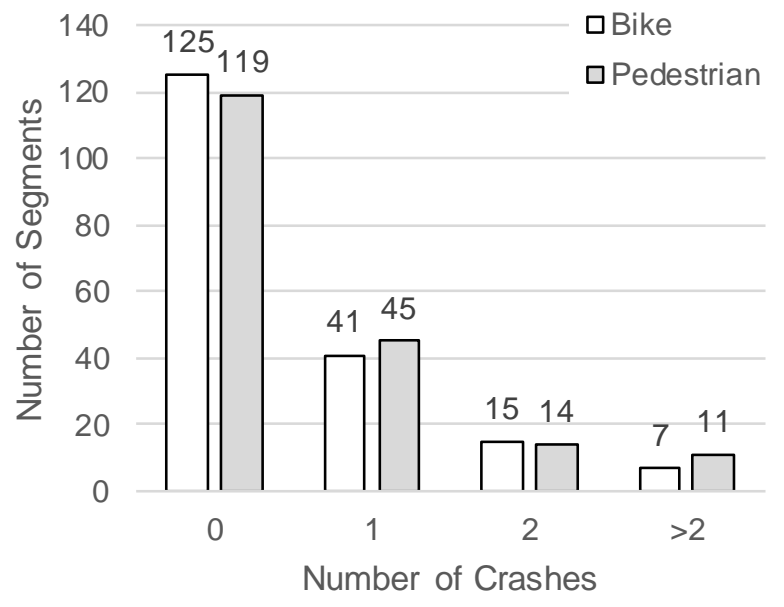

(a) Number of Segments by Crash Frequency

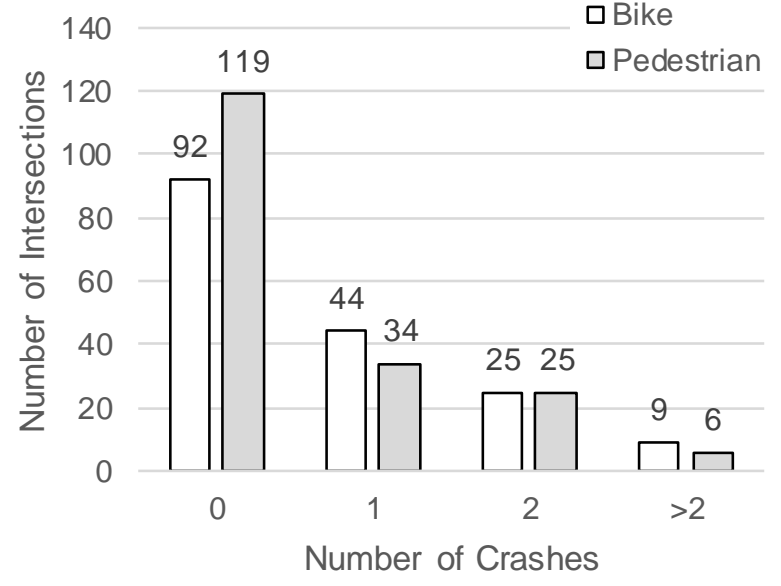

(b) Number of Intersections by Crash Frequency

FIGURE 1: Number of Segments and Intersections by Crash Frequency 
Wang Monsere Chen Wang
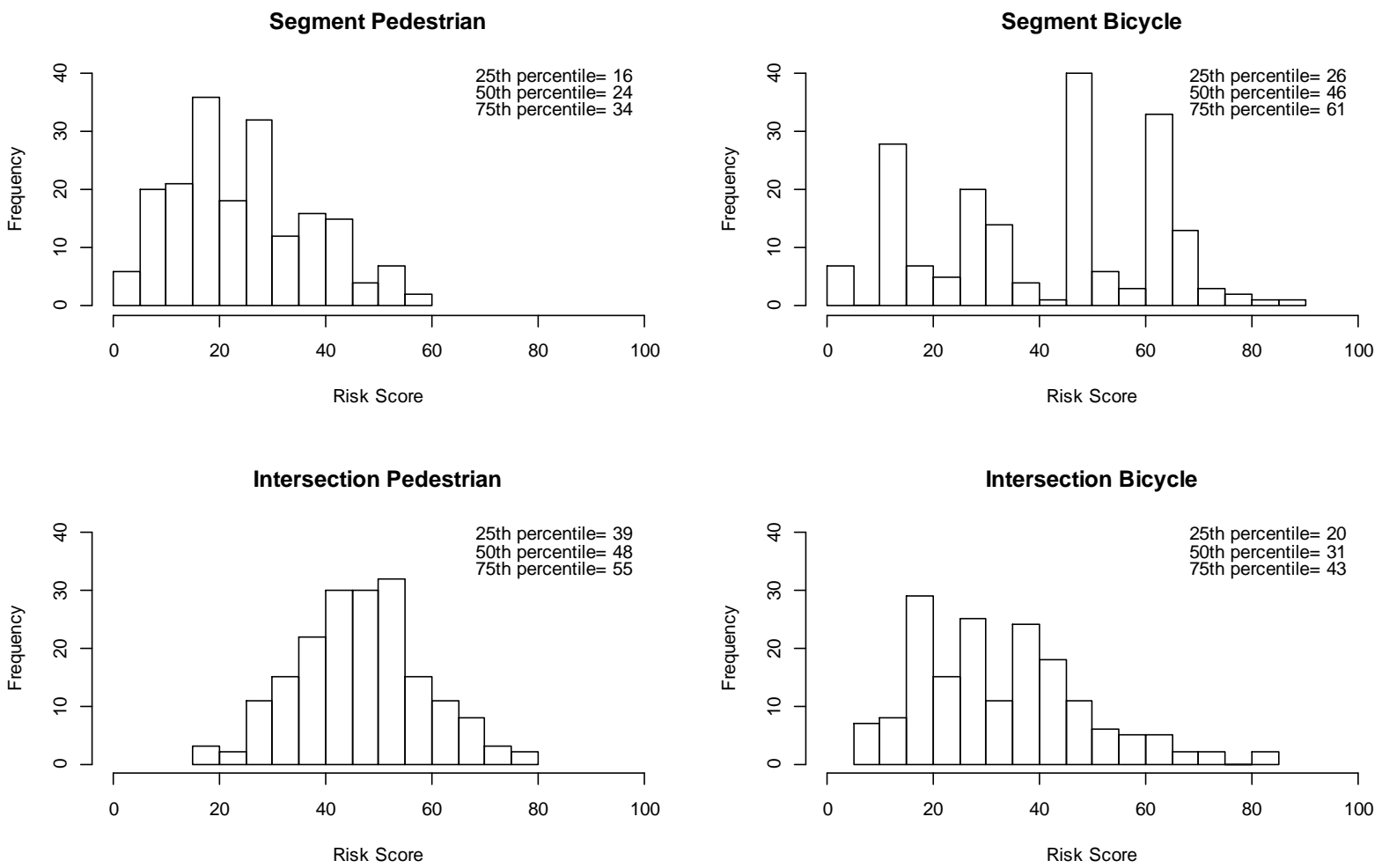

FIGURE 2 Risk-Score Distribution for Each Facility Type and User 